\title{
Medieval Tuscan glasses from Miranduolo, Italy: A multi-disciplinary study
}

\author{
Ivona Posedi ${ }^{\mathrm{a}, *}$, Zsófia Kertész ${ }^{\mathrm{b}}$, Pedro Barrulas ${ }^{\mathrm{a}}$, Vittorio Fronza ${ }^{\mathrm{c}}$, Nick Schiavon ${ }^{\mathrm{a}}$, José Mirão ${ }^{\mathrm{a}}$ \\ ${ }^{a}$ HERCULES Laboratory, University of Évora, Largo Marques do Marialva 8, 7000-809 Évora, Portugal \\ ${ }^{\mathrm{b}}$ Institute for Nuclear Research, Hungarian Academy of Sciences, Bem tér 18/c., P.O. Box 51, Debrecen 4026, Hungary \\ ${ }^{\mathrm{c}}$ Department of Historical Sciences and Cultural Heritage, University of Siena, Via Roma 56, Italy
}

\section{A R T I C L E I N F O}

\section{Keywords:}

Archaeometry

Archaeovitreology

Glass studies

Medieval glass

VP-SEM-EDS

PIXE/PIGE

LA-ICP-MS

\begin{abstract}
A B S T R A C T
Twenty transparent glass fragments from Miranduolo were analysed by Variable Pressure - Scanning Electron Microscopy - Energy Dispersive System (VP-SEM-EDS), Particle Induced X-Ray Emission and Particle Induced Gamma-Ray Emission (PIXE/PIGE) and Laser Ablation - Inductively Coupled Plasma - Mass Spectrometry (LAICP-MS). The fragments are dated from mid-13th to mid-14th century CE, when the first Tuscan glass-making workshops emerged. Miranduolo did not have an in situ glass-making workshop. Hence, the aim was to determine the glass production technology and raw material provenance. All the glasses are of plant ash (PA) sodalime-silica (Na-Ca-Si) composition, with eighteen being made with Levantine plant ash (LPA), one with Barilla plant ash (BPA), and one Na-Ca-Si glass with high magnesium and low potassium (HMg-LK). The production of LPA glasses can be distinguished according to the use of different sand typologies as former. It seems probable that glasses were produced regionally from multiple Tuscan glass factories.
\end{abstract}

\section{Introduction}

Medieval Tuscany is rich in archaeological remains and artefacts that were owned by aristocratic families (Valenti, 2008). From the beginning of the Medieval period, the hilltop villages - especially those of central Italy were newly built by the rural aristocracy, using the labour of peasants and accumulating agricultural goods. These sites turned into castles mostly during the 10th - early 11th century, as a result of a slow formation process (Valenti, 2008; Fronza and Valenti, 2015). Miranduolo is a castle whose residents were involved in agricultural and metallurgical industry.

Since the 13th century the historical Valdesa (Siena) was important for the establishment of glass-making (Cagno et al., 2010; Basso et al., 2009; Cagno et al., 2008). Germagnana, San Vettore and Santa Cristina in the territory of Gambassi were leading workshops of the period. The glassmaking and glass-working products were discovered in situ and were chemically analysed (Cagno et al., 2010; Casellato et al., 2003; Bianchin et al., 2005a; Bianchin et al., 2005b; Brianese et al., 2005). Besides Tuscany, the glass-making in Ligurian region was getting stronger at the time, while Venice had one of the most influential glass-making productions in Europe (Cagno et al., 2010; Cagno et al., 2012a; Verità, 2013).

\subsection{Archaeological context}

Miranduolo castle (Castello di Miranduolo) is a multi-layered medieval hill-top site (7th to 14th century CE with eight occupation periods) located on the Castagnoli slope in the Municipality of Chiusdino, Province of Siena, Tuscany region, Italy. More precisely, $3.9 \mathrm{~km}$ air distance south-southwest from Chiusdino and $7 \mathrm{~km}$ air distance south-west from the San Galgano Abbey. The extension of the 12 th and 13th century site is around $4650 \mathrm{~m}^{2}$, of which $3900 \mathrm{~m}^{2}$ are occupied by the village area with peasants huts, metallurgical factory, church and cemetery and $750 \mathrm{~m}^{2}$ are taken up by the summit area (cassero, Area 1) with the palace of the ruling noble family (Fig. 1, Table 1) (Valenti, 2008; Valenti, 2010; Castello di Miranduolo, n.d.).

Miranduolo castle was one of the centres in the region of historical Val di Merse, which was located between Siena and Volterra dioceses. Its location was important as the road, heading to the Tyrrhenian coast, crossed the Val di Merse. Besides the important geographical position, the area is rich with ore deposits of iron oxides, sphalerite, chalcopyrite and galena. Miranduolo itself, on the other hand, was erected in top of iron and copper minerals veins deposits (Valenti, 2008; Valenti, 2010).

In written sources, Miranduolo is defined as a castle for the first time in 1004, marking the final step of a gradual transition process to territorial sovereignty, expressed through severe investments that included building actions and physical protection by constructing defensive walls at the end of the 11th century. Comparing to the previous occupation periods, the life of the village was on decline during mid13th to mid-14th century (Period II). Possibly, during the second half of

\footnotetext{
* Corresponding author at: School of History and Heritage, University of Lincoln, Brayford Pool, Lincoln LN6 7TS, UK.

E-mail address: iposedi@lincoln.ac.uk (I. Posedi).
} 


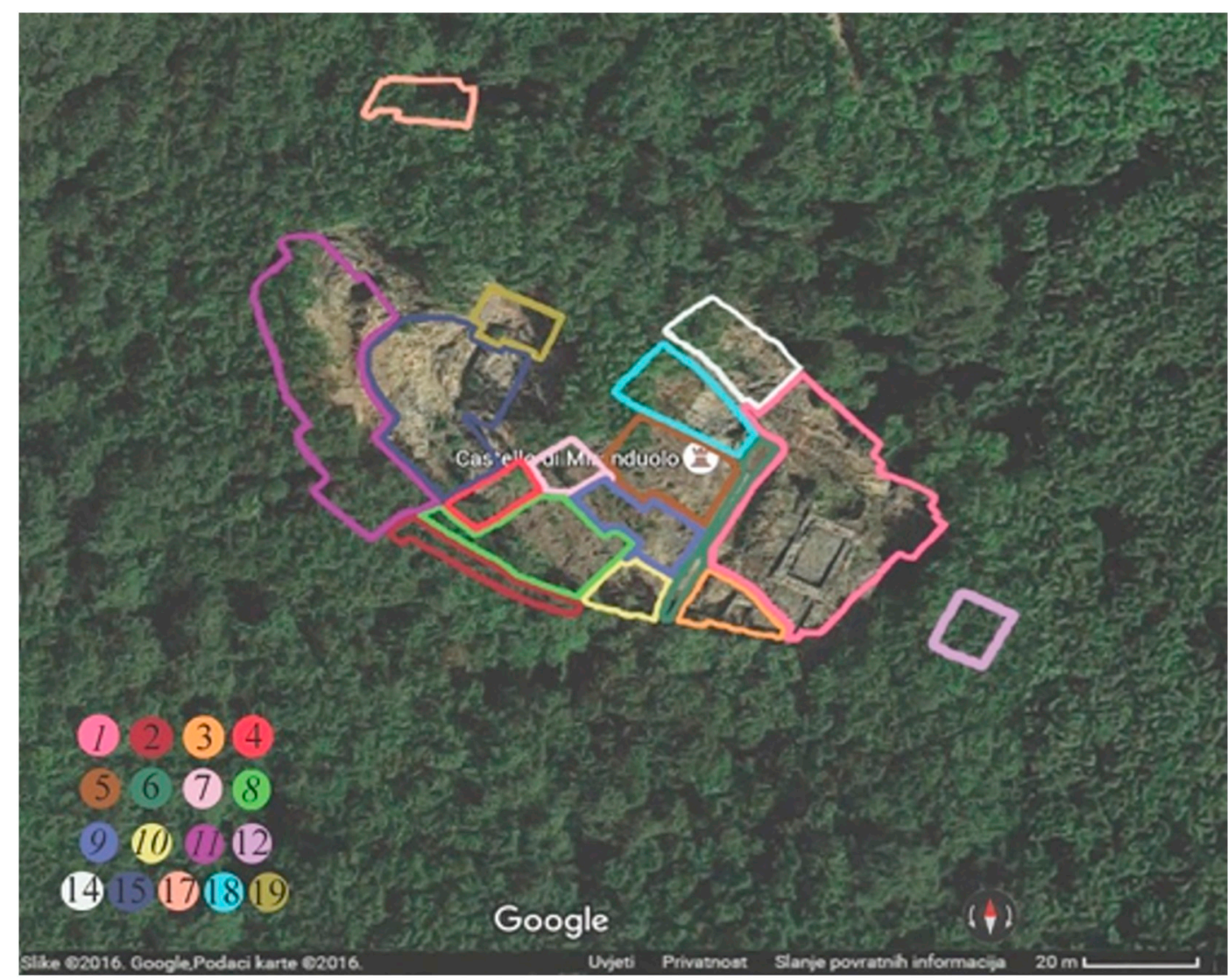

Fig. 1. Representation of the excavated areas at Miranduolo. Analysed glass fragments come from areas marked in italics. Satellite image via www.maps.google.hr.

Table 1

Periodisation of Miranduolo's Period II (Valenti, 2008).

\begin{tabular}{ll}
\hline Period II & \\
\hline Phase I & ca $1250-1278 \mathrm{CE}$ \\
Phase II & ca 1278-1333 CE \\
Phase III & ca $1333-1350 \mathrm{CE}$ \\
\hline
\end{tabular}

the 13th century, the site was used as a getaway residence of the Cantieri noble family (Valenti, 2008; Valenti, 2010).

\subsection{Aims}

The Period II (ca. 1250-1350 CE) tableware glasses were chosen for this study since it is the period when local Tuscan glass-making factories start to be established (Cagno et al., 2010; Basso et al., 2009; Cagno et al., 2008; Cagno et al., 2012b).

Hence, the aim was to determine:

$\diamond$ the glass production technology including the chemical composition, the use of decolourants and extent of recycling

$\diamond$ which glass-making workshops could have acted as probable suppliers of glass as no in situ workshop has been found at Miranduolo

$\diamond$ the presence of any socio-economic relevance connected to the chemical composition of the Miranduolo glass fragments

\section{Experimental}

\subsection{Samples and sampling strategy}

Twenty transparent glass fragments from Period II were selected for this study (Table 1) (Reperti vitrei Castello di Miranduolo, n.d.). The fragments were sampled by the principle of having a complete sequence of diverse colours representing all three phases in each single excavation area. The glasses analysed come from five excavation areas: 1 (cassero), 8, 9, 10 and 11 (Table 2, Fig. 1). The colours range from various hues of green, yellow to aqua and colourless. The fragments were classified as cups, bowls, bottles, closed forms, while some fragments were too small and could not be identified (Table 2).

Macroscopically, air bubbles are visible in all the samples. The preservation state of the glasses can be generally defined as very well preserved. Sample MD 191 shows a slight iridescence effect, while MD 139 and MD 259 show a strong iridescence effect and heavy flaking. The walls of the vessels were sampled, except in the case of MD 173, MD 191 and MD 276 which are ring bottoms of the cups (Table 2).

After being photographed, the samples were dry cut, set in epoxy resin blocks and polished.

\subsection{VP-SEM-EDS}

Variable Pressure - Scanning Electron Microscopy - Energy Dispersive Spectroscopy (VP-SEM-EDS) was used to evaluate the homogeneity of the pristine glass and the presence and intensity of glass deterioration (de-alkalisation). Additionally, these results are semiquantitative and aided in selection of glass certified reference materials for quantification of results by PIXE/PIGE and LA-ICP-MS. Cross-sections embedded in epoxy resin were analysed with a HITACHI S3700N VP-SEM equipped with a Bruker AXS X-Flash ${ }^{\circledR} 5010$ Silicon Drift Detector (126 eV Spectral Resolution at MnKa Full Maximum Half Width FMHW) for EDS. The use of VP-SEM eliminates carbon coating need and it is less time consuming. Quantitative standardless PB/ZAF elemental analysis was made using the Bruker ESPRIT 1.9 software. The operating conditions for SEM-EDS analysis were: backscattered electron 
Table 2

Sample specifications. $\mathrm{ni}=$ not identified.

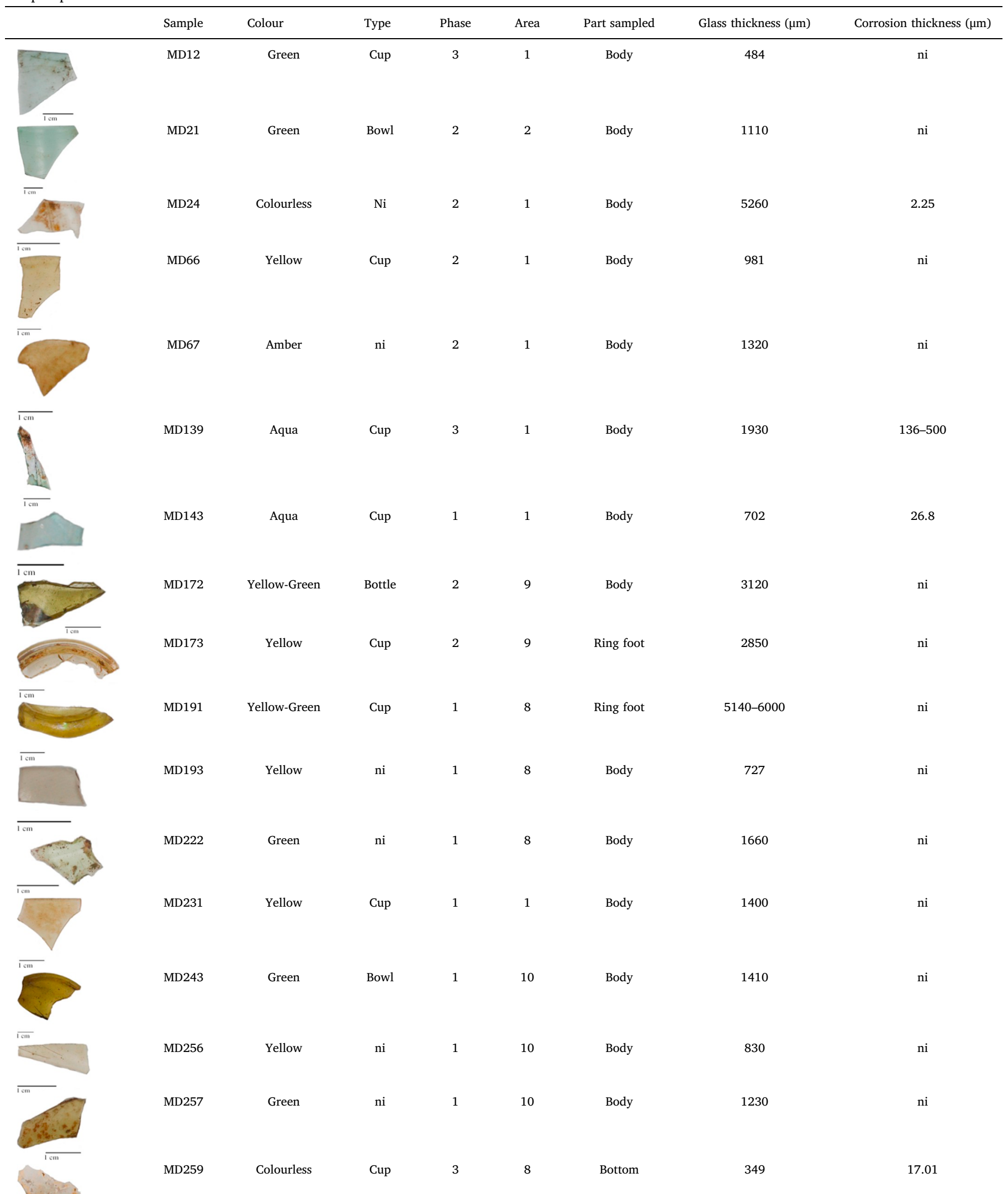


Table 2 (continued)

\begin{tabular}{|c|c|c|c|c|c|c|c|c|}
\hline & Sample & Colour & Type & Phase & Area & Part sampled & Glass thickness $(\mu \mathrm{m})$ & Corrosion thickness $(\mu \mathrm{m})$ \\
\hline & MD261 & Aqua & ni & 3 & 11 & Body & 1020 & $\mathrm{ni}$ \\
\hline & MD272 & Amber & Cup & 3 & 11 & Body & 1250 & $\mathrm{ni}$ \\
\hline & MD276 & Green & Cup & 1 & 11 & Ring foot & 15,000 & $\mathrm{ni}$ \\
\hline
\end{tabular}

mode (BSEM), pressure $40 \mathrm{~Pa}, 20 \mathrm{kV}$ accelerating voltage, $10-14 \mathrm{~mm}$ working distance. An area measurement per sample was performed for $60 \mathrm{~s}$ in real time. The data are presented as oxides in weight percent (wt $\%)$.

\subsection{PIXE/PIGE}

The Particle Induced X-Ray Emission and Particle Induced GammaRay Emission (PIXE/PIGE) analysis was carried out at MTA Atomki, Debrecen, Hungary at the scanning nuclear microprobe installed on the $0^{\circ}$ beamline of the $5 \mathrm{MV}$ Van de Graaff accelerator (Brianese et al., 2005). The measurement setup included four detectors. For PIXE two XRay detectors were placed at $135^{\circ}$ geometry to the incidence beam: an SDD detector with AP3.3 ultra-thin polymer window (SGX Sensortech) with $30 \mathrm{~mm}^{2}$ active surface area for measurement of low and medium energy X-rays (0.2-12 keV, $\mathrm{Z}>5$ ); a Gresham type Be-window $\mathrm{Si}(\mathrm{Li})$ $\mathrm{X}$-ray detector with $30 \mathrm{~mm}^{2}$ active surface area equipped with an additional kapton filter of $125 \mu \mathrm{m}$ thickness for measurement of medium and high energy X-rays (3-30 keV, Z > 19). For PIGE a Canberra HPGe $40 \%$ gamma-Ray detector was placed at $45^{\circ}$ with respect to the incidence beam direction and $11 \mathrm{~cm}$ distance from the sample, outside the vacuum chamber. The accumulated charge was monitored using a beam chopper equipped with a collimated PIN diode.

All the signals of the detectors were recorded event by event in list mode by the Oxford type OMDAQ data acquisition system. A detailed description of the measurement setup can be found in (Simon et al., 2011).

A proton beam of $3.2 \mathrm{MeV}$ focused down to $\sim 5 \mu \mathrm{m} \times 5 \mu \mathrm{m}$ with a current of 50-100 pA was applied to irradiate the samples. On each sample measurements were carried out on 2-4 spots with a size of $1 \mathrm{~mm} \times 1 \mathrm{~mm}$ by scanning the beam on the sample. Firstly, elemental maps on the aforementioned $1 \mathrm{~mm} \times 1 \mathrm{~mm}$ areas were recorded, and if there was a necessity, a homogeneous area was selected for further measurements. The accumulated charge on each spot was $0.1-0.15 \mu \mathrm{C}$. In the case of samples MD 139, MD 143 and MD 259 that display corrosion layers, further maps of the corrosion layer were recorded with a scan size adjusted to the size of the corrosion layer.

To test the quality and the precision of the dose measurement and of the quantification measurements were carried out on standard reference materials (SRM) The calibration of the beam chopper was done at the same time. The SRMs included NIST 610, Corning A and Corning B glasses (Inline Supplementary Table S1), a series of pure metals and a layered sample of $6 \mu \mathrm{m}$ thick Ti foil on $50 \mu \mathrm{m} \mathrm{Ni}$ (Wagner et al., 2012; Trace Elements (wafer form), n.d.; Brill, 1999a).

The evaluation of the PIXE spectra was done with the GUPIXWIN software (Campbell et al., 2010) Samples were treated as thick samples. Firstly, the matrix composition was determined from the SDD detector spectra using the iterative matrix solution method. Afterwards, the spectra recorded by the Be-window $\mathrm{Si}(\mathrm{Li}) \mathrm{X}$-ray detector were analysed in trace mode, implementing the previously obtained matrix and the measured irradiation dose. In the 3.0-8.5 keV range there are the intensive X-ray lines such as $\mathrm{K} \mathrm{K}_{\alpha}$, Ca $\mathrm{K}_{\alpha}$, Ti $\mathrm{K}_{\alpha}$, Fe $\mathrm{K}_{\alpha}$ which were common for both detectors, therefore these were used for elemental concentration normalization, if it was necessary. Generally, the difference between the concentrations obtained independently for the two PIXE detectors was $<5 \%$.

Besides evaluating the spectra of the individual measurement areas spectra measured on the same sample were summed in order to reduce the detection limits. This way the detection limits (MDL) were reduced by $30-50 \%$ comparing to the MDL of the spectra corresponding to a one-point analysis. By measuring in several points, the homogeneity of the samples was also investigated.

The analytical uncertainty of PIXE (including the fitting process uncertainty) for major elements was $\sim 2-5 \%$, while for minor and trace elements $\sim 10-15 \%$. The data is presented as oxides in wt $\%$ or as elements expressed in ppm.

Since the information depth of PIXE for light elements is only few micrometres, particle induced gamma emission (PIGE) was used to gather information about the concentration of $\mathrm{Na}$ and $\mathrm{Mg}$ from the deeper layers of the glass. NIST 610 and Corning A were used as calibration standards (Wagner et al., 2012; Trace Elements (wafer form), n.d.; Brill, 1999a).

The concentration obtained from PIGE was in a very good agreement (within uncertainty) with the PIXE results, showing homogeneity down to $100 \mu \mathrm{m}$.

\subsection{LA-ICP-MS}

No further sample preparation was required as laser ablation mode was used. The ablation was performed by Cetac Technologies LSX$213 \mathrm{G}^{+}$coupled with Agilent 8800 Triple Quadrupole Instrument. Instrument specifications and conditions are presented in Table 3.

The PIXE/PIGE provided the silica concentration that was converted into $\mathrm{SiO}_{2}$ and used as internal standard for the quantification process by Laser Ablation - Inductively Coupled Plasma - Mass Spectrometry (LAICP-MS).

The data evaluation for glass standard materials included the calculation of average, recovery (\%) and drift (\%). Recoveries of 90-110\%, and a drift $\leq 10 \%$ were accepted as a result that did not require any corrections.

Each measurement campaign consisted of 3 spot analyses for each glass standard material and 4 spot analyses for glass samples. Between 8 and 12 glass sample measurements, three replicates of the certified references materials were performed in order to check for any potential instrumental drift.

NIST 610 and 612 were used as CRM's (Inline Supplementary Table S1) (Trace Elements (wafer form), n.d.). Mg, P, K, Ti, Mn, Zn, Sr and Ba were calculated using NIST 610 due to their higher concentrations. Remaining elements were quantified using NIST 612. Major and minor elements were normalised to $100 \mathrm{wt} \%$ in oxides. 
Table 3

LA-ICP-MS instrument specifications and analysis conditions.

\begin{tabular}{|c|c|}
\hline & Laser system \\
\hline $\begin{array}{l}\text { Manufacturer and } \\
\text { model }\end{array}$ & Cetac Technologies LSX-213 G2 ${ }^{+}$ \\
\hline Laser type & Q-switched Nd:YAG laser \\
\hline Wavelength & $213 \mathrm{~nm}$ \\
\hline Repetition rate $(\mathrm{Hz})$ & 20 \\
\hline Ablation mode & Single-spot (600 shots) \\
\hline Carrier gas (flow rate) & Helium $(1 \mathrm{~L} / \mathrm{min})$ \\
\hline Pre-ablation time (s) & 15 \\
\hline Ablation time (s) & 30 \\
\hline Wash out (s) & 10 \\
\hline \multirow[t]{2}{*}{ Beam diameter $(\mu \mathrm{m})$} & 50 \\
\hline & Spectrometer \\
\hline $\begin{array}{l}\text { Manufacturer and } \\
\text { model }\end{array}$ & Agilent 8800 Triple Quadrupole \\
\hline RF power (W) & 1550 \\
\hline $\begin{array}{l}\text { Argon dilution gas (L/ } \\
\text { min) }\end{array}$ & 0.7 \\
\hline $\begin{array}{l}\text { Argon plasma gas (L/ } \\
\text { min) }\end{array}$ & 15 \\
\hline Sample depth (mm) & 4 \\
\hline Mode & MS/MS \\
\hline \multirow{7}{*}{$\begin{array}{l}\text { Dwell time (ms) - } \\
\text { isotopes }\end{array}$} & $5-{ }^{23} \mathrm{Na},{ }^{24} \mathrm{Mg},{ }^{27} \mathrm{Al},{ }^{28} \mathrm{Si},{ }^{39} \mathrm{~K},{ }^{44} \mathrm{Ca},{ }^{56} \mathrm{Fe}$ \\
\hline & $\begin{array}{l}10-{ }^{43} \mathrm{Ca},{ }^{47} \mathrm{Ti},{ }^{52} \mathrm{Cr},{ }^{55} \mathrm{Mn},{ }^{57} \mathrm{Fe},{ }^{59} \mathrm{Co},{ }^{60} \mathrm{Ni},{ }^{63} \mathrm{Cu},{ }^{66} \mathrm{Zn}, \\
{ }^{75} \mathrm{As},{ }^{85} \mathrm{Rb},{ }^{88} \mathrm{Sr},{ }^{89} \mathrm{Y},{ }^{90} \mathrm{Zr},{ }^{118} \mathrm{Sn}\end{array}$ \\
\hline & $\begin{array}{l}20-{ }^{31} \mathrm{P},{ }^{51} \mathrm{~V},{ }^{93} \mathrm{Nb},{ }^{121} \mathrm{Sb},{ }^{137} \mathrm{Ba},{ }^{139} \mathrm{La},{ }^{140} \mathrm{Ce},{ }^{141} \mathrm{Pr}, \\
{ }^{146} \mathrm{Nd},{ }^{147} \mathrm{Sm},{ }^{153} \mathrm{Eu},{ }^{147} \mathrm{Gd},{ }^{159} \mathrm{~Tb},{ }^{163} \mathrm{Dy}, 1^{65} \mathrm{Ho}, \\
{ }^{166} \mathrm{Er},{ }^{169} \mathrm{Tm},{ }^{172} \mathrm{Yb},{ }^{175} \mathrm{Lu},{ }^{178} \mathrm{Hf},{ }^{208} \mathrm{~Pb},{ }^{232} \mathrm{Th},{ }^{238} \mathrm{U}\end{array}$ \\
\hline & Data processing software \\
\hline & Glitter v 4.4 .2 \\
\hline & Certified standards \\
\hline & NIST 610 and NIST 612 \\
\hline
\end{tabular}

\section{Results}

\subsection{Homogeneity}

Both VP-SEM-EDS and PIXE/PIGE analyses determined that all Miranduolo samples are homogeneous (Fig. 2). This was further confirmed by LA-ICP-MS as the data of four points of the same sample did not show compositional discrepancies. The samples thickness varies due to different parts of the container were sampled (Table 2).

The thinnest sample was blown to $350 \mu \mathrm{m}$. The glass blower would need to have experience of couple of decades in order to blow the glass this thin. There are no inclusions nor frequent presence of air bubbles. Only four samples display corrosion layers.

\subsection{Classification and nomenclature}

All glasses have soda-lime-silica (Na-Ca-Si) composition as determined by all three analytical techniques (Inline Supplementary Table $\mathrm{S} 1$ ). The $\mathrm{K}_{2} \mathrm{O}$ and $\mathrm{MgO}$ concentrations are above $1.5 \mathrm{wt} \%$ and classify Miranduolo glasses as plant ash (PA) Na-Ca-Si glasses. The origin of plant ash glasses can be determined according to the $\mathrm{K}_{2} \mathrm{O}$ concentration. Glasses with $1.5<\mathrm{K}_{2} \mathrm{O}<4.5 \mathrm{wt} \%$ are assumed to be made with Levantine plant ash (LPA) (Cagno et al., 2008). Barilla plant ash (BPA) was used when $4.5<\mathrm{K}_{2} \mathrm{O}<8 \mathrm{wt} \%$ (Cagno et al., 2008; Vandini et al., 2018). The plant ashes could have been purified which would include the treatment with boiling water (Cagno et al., 2008; Casellato et al., 2003). The precipitated salts were less soluble and the original $\mathrm{CaO}$ and $\mathrm{MgO}$ content diminished (Cagno et al., 2008; Casellato et al., 2003). Hence, Cagno et al. (2008) indicate the distinction between purified and impurified PA according to the $\mathrm{CaO}$ concentration. Glasses containing $\mathrm{CaO}<7 \mathrm{wt} \%$ indicate the use of purified ashes, and glasses with $\mathrm{CaO}>7 \mathrm{wt} \%$ have impurified plant ashes added as a flux (Cagno et al., 2008).

To avoid creating new terminology and for these purposes only, Cagno et al. (2008) terminology for purified and impurified plant ashes will be continuously used throughout the paper.

\subsubsection{Glass sub-groups}

The differences in the $\mathrm{CaO}$ concentrations between the techniques need to be highlighted because $\mathrm{CaO}$ is used a classifying discriminant. The $\mathrm{CaO}$ values by PIXE/PIGE are generally lower than the VP-SEMEDS and LA-ICP-MS (Inline Supplementary Table S1). This could be a reflectance of the methodology used: PIXE/PIGE has a different depth of analysis, spot size and different sensitivity for detecting lighter elements than VP-SEM-EDS and LA-ICP-MS (Janssens, 2013; Pollard and Heron, 2008). Because the recovery of calcium values was more precise with LA-ICP-MS than PIXE/PIGE, and EDS being semi-quantifying, the distinction between purified and impurified plant ashes throughout this paper will be based on and LA-ICP-MS data (Fig. 3). The analysis determined that eighteen Miranduolo glasses are made from LPA: impurified and purified (Fig. 3). One glass is made with BPA (Fig. 3). MD 139 is classified as High Magnesium - Low Potassium Na-Ca-Si glass (HMg-LK) due to $\mathrm{K}_{2} \mathrm{O}<1.5 \mathrm{wt} \%$ and $\mathrm{MgO}>1.5 \mathrm{wt} \%$ (Fig. 3). This sub-group has only been acknowledged by Franjić (Franjić, 2018) and it is not often encountered. It is generally overseen such as on Roman La Négade (sample 2, LN, pu, v) (Henderson, 1988), early medieval and high medieval sites of Piazza Bovio, Napoli (sample v12) (De Francesco et al., 2014), San Genesio (sample 52) (Cagno et al., 2012b), Rocca di Campiglia (sample t_63) (Cagno et al., 2010), Savona (sample 4121) (Cagno et al., 2012a), Nogara (samples OF6a, OR3, PR2b, PR5) (Silvestri and Marcante, 2011) and Cordoba, Spain (samples COR1,
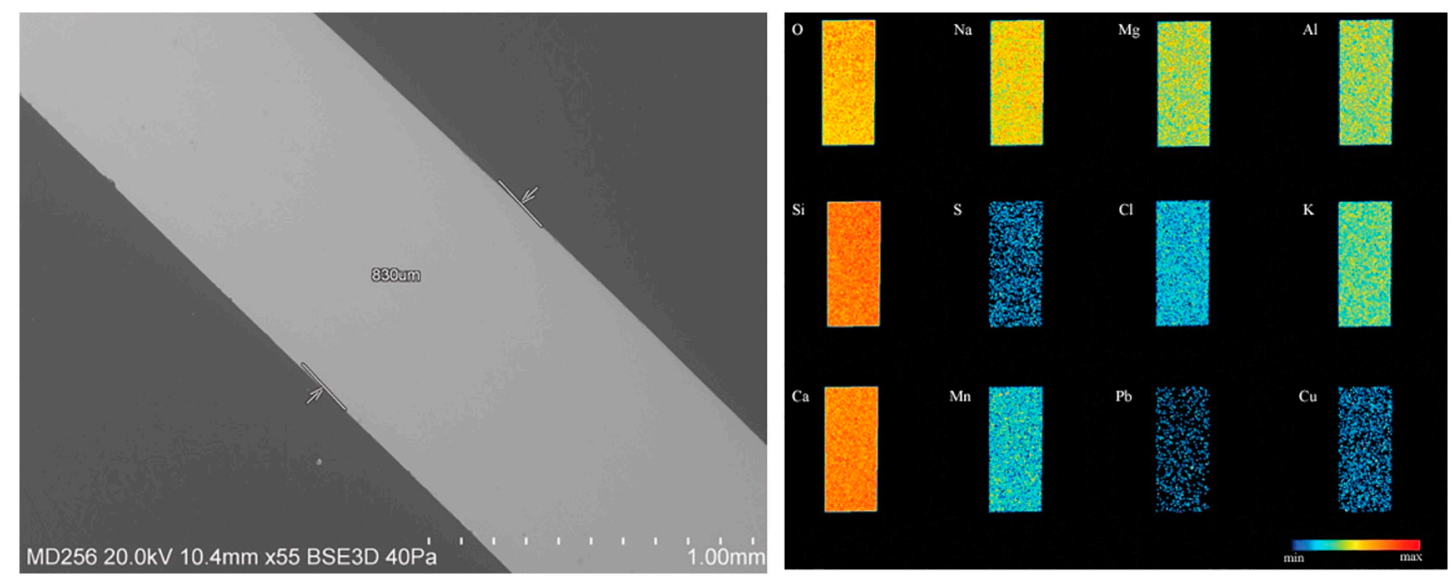

Fig. 2. BSE image of MD 256 (left). PIXE/PIGE chemical map of selected area of MD 12 (right). 


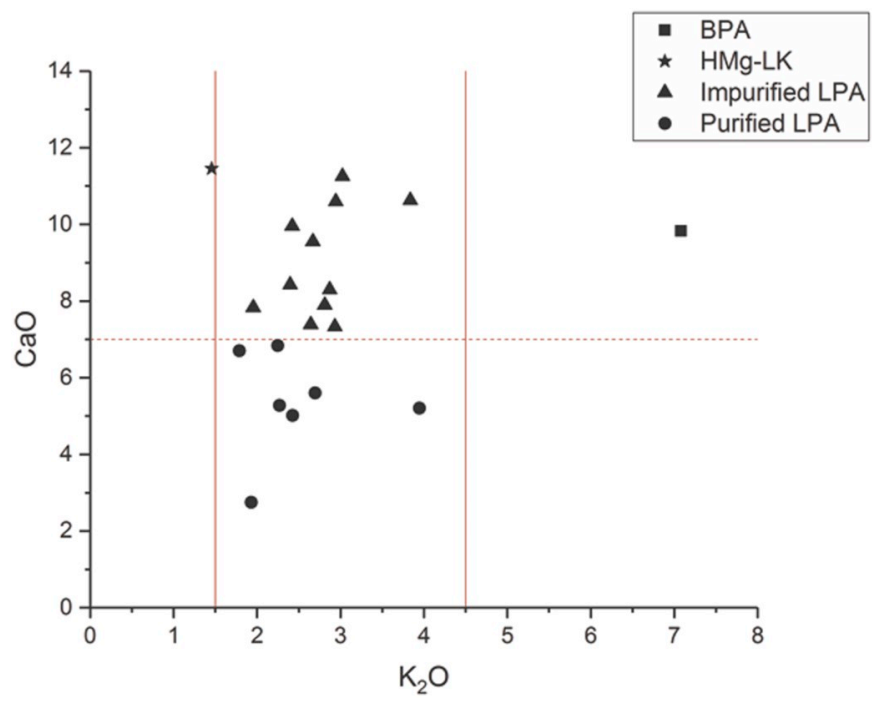

Fig. 3. The distinction of four Miranduolo soda-lime-silica glass subgroups based on LA-ICP-MS data in $\mathrm{wt} \%$.

COR14, COR18 and COR24) (Duckworth et al., 2015).

The difference in average composition of impurified and purified LPA glasses is notable as well as the difference in the $\mathrm{Na}_{2} \mathrm{O} / \mathrm{K}_{2} \mathrm{O}$ and $\mathrm{K}_{2} \mathrm{O} / \mathrm{CaO}$ (Inline Supplementary Table S1).

\subsection{Different plant ashes or different sands as raw materials?}

The basic glass recipe seems to be in accordance with other Italian glasses (Brianese et al., 2005; Verità, 2013; Brill, 1999a; Vandini et al., 2018; Schibille and Freestone, 2013; Brill, 1999b; Brill and Pongracz, 2004) (Figs. 4, 5). The purified LPA glasses with $\mathrm{CaO}<7 \mathrm{wt} \%$ and $\mathrm{Sr} \leq 420 \mathrm{ppm}$ have a constant $\mathrm{MgO}$ concentration between 1.5 and $1.8 \mathrm{wt} \%$. Therefore, the $\mathrm{MgO}$ concentration could be an indication of plant purification process.

The analysis of plant ashes (Barkoudah and Henderson, 2008) has proven the existence of strong positive correlation of $\mathrm{K}_{2} \mathrm{O}-\mathrm{CaO}$ and $\mathrm{K}_{2} \mathrm{O}-\mathrm{MgO}, \mathrm{CaO}-\mathrm{Ba}, \mathrm{MgO}-\mathrm{Ba}, \mathrm{K}_{2} \mathrm{O}-\mathrm{Ba}$ and $\mathrm{CaO}-\mathrm{MgO}$ in Salsola plant ashes. The non-Salsola plant ashes only have moderate positive correlation of $\mathrm{K}_{2} \mathrm{O}-\mathrm{MgO}$ and $\mathrm{CaO}-\mathrm{Ba}$.

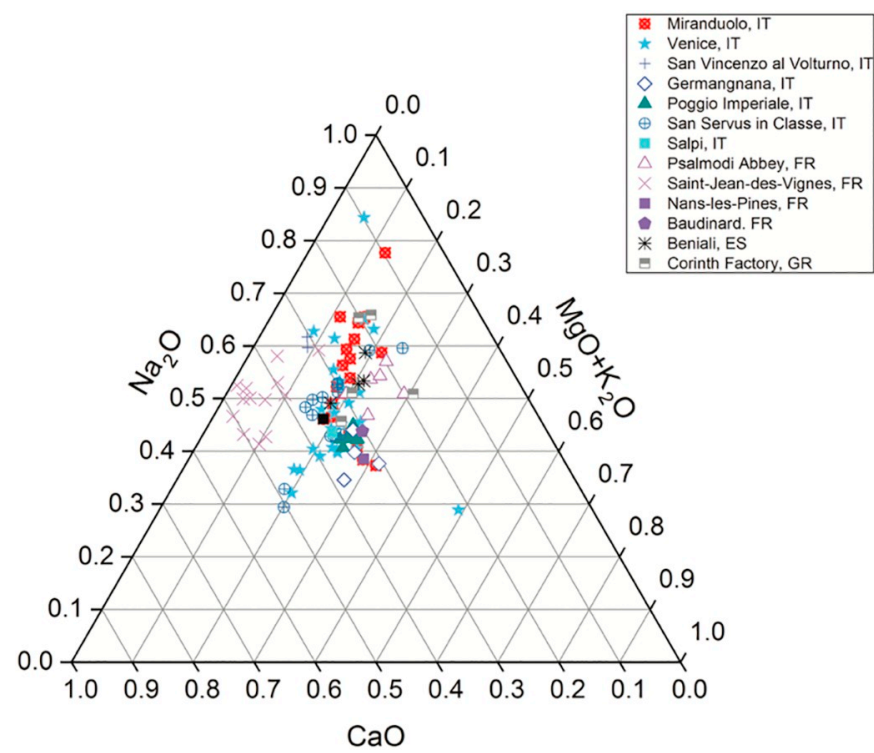

Fig. 4. Ternary plot of $\mathrm{CaO}-\mathrm{MgO}+\mathrm{K}_{2} \mathrm{O}-\mathrm{Na}_{2} \mathrm{O}$ of 13 th-14th century glasses in $\mathrm{wt} \%$ (LA-ICP-MS).

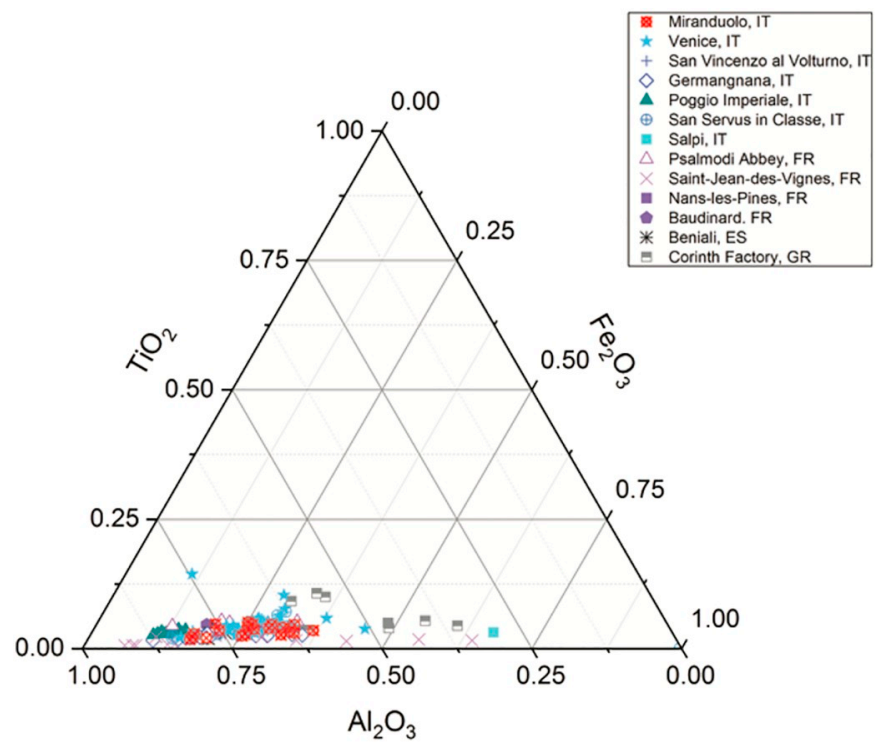

Fig. 5. Ternary plot of $\mathrm{Al}_{2} \mathrm{O}_{3}-\mathrm{TiO}_{2}-\mathrm{Fe}_{2} \mathrm{O}_{3}$ of 13 th-14th century glasses in wt $\%$ (LA-ICP-MS).

Miranduolo's impurified LPA glasses display the following:

$\diamond$ no correlation of $\mathrm{K}_{2} \mathrm{O}-\mathrm{MgO}, \mathrm{K}_{2} \mathrm{O}-\mathrm{Ba}$

$\diamond$ a moderate positive correlation of $\mathrm{K}_{2} \mathrm{O}-\mathrm{CaO}$ and $\mathrm{CaO}-\mathrm{Ba}$

$\diamond$ a strong positive relationship between $\mathrm{CaO}-\mathrm{Mg}$ and $\mathrm{MgO}-\mathrm{Ba}$.

Therefore, this could indicate that

$\diamond$ both Salsola and non-Salsola plant ashes were added to the melt $\checkmark$ the calcium content is related to the silica source or to an intentional adding of calcium source in form of shell fragments or limestone, and not to the plant ashes

$\checkmark$ a combination of both types of plant ashes was mixed with calcium rich sands.

The high calcium content (10.6-14.2 wt $\%$ ) of the sands have been found in the region at La Casina La Cava quarry near Gambassi (Casellato et al., 2003). This sand was, experimentally, been washed and both heavier and lighter parts chemically analysed. The heavier part of the washed sand has sufficiently lower amount of magnesium (0.6 wt $\%)$ and higher amount of calcium (14.2 wt\%) comparing to the lighter part (1.7 wt $\%$ and $10.6 \mathrm{wt} \%$ ) (Casellato et al., 2003).

Strontium behaves related to calcium in most geochemical environments. In impurified LPA the strontium is higher than in the purified LPA (Table 4).

Hence, it seems possible that the sand purification process by washing it with water, could have had an impact on the compositional differences. To understand if this sand was used to make Miranduolo glasses trace element analysis of the sand would be necessary.

\subsection{Minor and trace elements}

\subsubsection{The extent of recycling}

The extent of recycling is usually displayed by showing elevated concentrations of $\mathrm{Pb}, \mathrm{Cu}, \mathrm{Zn}, \mathrm{Sb}, \mathrm{Sn}$ (> circa $100 \mathrm{ppm}$ ) (Silvestri and Marcante, 2011).

Miranduolo glasses do not show these tendencies. Exceptions are:

$\diamond \mathrm{MD} 172$ with $\mathrm{Cu}$ and $\mathrm{Pb}>100 \mathrm{ppm}$;

$\checkmark$ MD 257 with $\mathrm{Cu}, \mathrm{Sb}$ and $\mathrm{Cu}>100 \mathrm{ppm}$;

$\diamond$ MD 256 with $\mathrm{Cu}, \mathrm{Zn}, \mathrm{Sb}, \mathrm{Pb}>100$ ppm (Table 4). 
Table 4

LA-ICP-MS data. Oxides are represented in $\mathrm{wt} \%$ and elements as $\mathrm{ppm}$.

\begin{tabular}{|c|c|c|c|c|c|c|c|c|c|c|c|c|c|c|c|c|c|c|}
\hline Glass group & Sample & Colour & Type & Phase & Area & $\begin{array}{l}\text { Part } \\
\text { sampled }\end{array}$ & $\begin{array}{l}\text { Glass } \\
\text { thickness } \\
\mu \mathrm{m}\end{array}$ & $\begin{array}{l}\text { Corrosion } \\
\text { thickness } \\
\mu \mathrm{m}\end{array}$ & $\mathrm{Na}_{2} \mathrm{O}$ & $\mathrm{MgO}$ & $\mathrm{Al}_{2} \mathrm{O}_{3}$ & $\mathrm{SiO}_{2}$ & $\mathrm{P}_{2} \mathrm{O}_{5}$ & $\mathrm{~K}_{2} \mathrm{O}$ & $\mathrm{CaO}$ & $\mathrm{TiO}_{2}$ & $\mathrm{MnO}$ & $\mathrm{Fe}_{2} \mathrm{O}_{3}$ \\
\hline BPA & MD 243 & Green & bowl & 1 & 10 & Body & 1410 & nd & 11.7 & 2.73 & 2.87 & 62.1 & 0.76 & 7.08 & 9.83 & 0.17 & 1.05 & 1.77 \\
\hline HMg-LK & MD 139 & Aqua & cup & 3 & 1 & Body & 1930 & $136-500$ & 14.8 & 4.45 & 3.25 & 62.6 & 0.57 & 1.46 & 11.5 & 0.11 & 0.08 & 1.14 \\
\hline Impurified LPA & MD 12 & Green & cup & 3 & 1 & Body & 484 & nd & 13.2 & 5.66 & 4.37 & 61.2 & 0.64 & 2.94 & 10.6 & 0.11 & 0.12 & 1.10 \\
\hline Impurified LPA & MD 21 & Green & bowl & 2 & 2 & Body & 1110 & nd & 12.4 & 5.42 & 5.28 & 60.4 & 0.64 & 3.84 & 10.6 & 0.14 & 0.15 & 1.13 \\
\hline Impurified LPA & MD 24 & Colourless & nd & 2 & 1 & Body & 5260 & 2.25 & 17.4 & 1.91 & 2.21 & 66.1 & 0.31 & 2.64 & 7.39 & 0.12 & 0.78 & 1.14 \\
\hline Impurified LPA & MD 66 & Yellow & cup & 2 & 1 & Body & 981 & nd & 16.4 & 2.81 & 2.66 & 63.0 & 0.60 & 2.67 & 9.55 & 0.11 & 0.85 & 1.29 \\
\hline Impurified LPA & MD 143 & Aqua & cup & 1 & 1 & Body & 702 & 26.8 & 13.3 & 4.87 & 4.66 & 63.0 & 0.51 & 2.42 & 10.0 & 0.10 & 0.16 & 0.98 \\
\hline Impurified LPA & MD 173 & Yellow & cup & 2 & 9 & Ring foot & 2850 & nd & 12.7 & 2.36 & 2.39 & 70.0 & 0.41 & 2.40 & 8.43 & 0.09 & 0.40 & 0.86 \\
\hline Impurified LPA & MD 191 & Yellow-Green & cup & 1 & 8 & Ring foot & $5140-6000$ & nd & 16.3 & 1.93 & 2.16 & 66.3 & 0.45 & 2.81 & 7.90 & 0.10 & 0.92 & 1.16 \\
\hline Impurified LPA & MD 231 & Yellow & cup & 1 & 1 & Body & 1400 & nd & 14.2 & 2.47 & 3.97 & 65.7 & 0.54 & 2.87 & 8.30 & 0.14 & 0.97 & 0.85 \\
\hline Impurified LPA & MD 257 & Green & nd & 1 & 10 & Body & 1230 & nd & 18.3 & 2.47 & 3.81 & 63.2 & 0.30 & 2.25 & 6.84 & 0.26 & 1.20 & 1.43 \\
\hline Impurified LPA & MD 259 & Colourless & cup & 3 & 8 & Bottom & 349 & 17.0 & 15.3 & 3.40 & 1.55 & 64.4 & 0.25 & 3.02 & 11.3 & 0.10 & 0.33 & 0.41 \\
\hline Impurified LPA & MD 272 & Amber & cup & 3 & 11 & Body & 1250 & nd & 15.5 & 3.44 & 2.44 & 66.4 & 0.47 & 1.95 & 7.83 & 0.13 & 0.96 & 0.94 \\
\hline Impurified LPA & MD 276 & Green & cup & 1 & 11 & Ring foot & 15,000 & nd & 16.6 & 1.97 & 3.10 & 65.8 & 0.38 & 2.93 & 7.33 & 0.14 & 0.92 & 0.87 \\
\hline Purified LPA & MD 67 & Amber & nd & 2 & 1 & Body & 1320 & nd & 22.1 & 1.68 & 3.91 & 64.2 & 0.28 & 1.93 & 2.75 & 0.29 & 0.82 & 2.08 \\
\hline Purified LPA & MD 172 & Yellow-Green & bottle & 2 & 9 & Body & 3120 & nd & 18.7 & 1.69 & 3.23 & 65.1 & 0.34 & 2.70 & 5.60 & 0.20 & 0.87 & 1.57 \\
\hline Purified LPA & MD 193 & Yellow & nd & 1 & 8 & Body & 727 & nd & 17.2 & 1.62 & 3.88 & 67.1 & 0.25 & 2.43 & 5.02 & 0.27 & 0.55 & 1.72 \\
\hline Purified LPA & MD 222 & Green & nd & 1 & 8 & Body & 1660 & nd & 16.4 & 1.53 & 3.24 & 68.8 & 0.25 & 2.27 & 5.28 & 0.19 & 0.61 & 1.41 \\
\hline Purified LPA & MD 256 & Yellow & nd & 1 & 10 & Body & 830 & nd & 15.5 & 1.76 & 3.31 & 67.6 & 0.46 & 3.95 & 5.21 & 0.24 & 0.77 & 1.19 \\
\hline Purified LPA & MD 261 & Aqua & nd & 3 & 11 & Body & 1020 & nd & 19.0 & 1.51 & 3.58 & 64.9 & 0.22 & 1.79 & 6.70 & 0.21 & 0.83 & 1.30 \\
\hline
\end{tabular}

\begin{tabular}{|c|c|c|c|c|c|c|c|c|c|c|c|c|c|c|c|c|c|c|}
\hline Sample & $\mathrm{V}$ & $\mathrm{Cr}$ & & Co & $\mathrm{Ni}$ & $\mathrm{Cu}$ & $\mathrm{Zn}$ & As & $\mathrm{Rb}$ & & $\mathrm{Sr}$ & $\mathrm{Y}$ & $\mathrm{Zr}$ & $\mathrm{Nb}$ & & \multicolumn{2}{|r|}{$\mathrm{Sb}$} & $\mathrm{Ba}$ \\
\hline MD 243 & 21 & 23 & & 7 & 19 & 72 & 133 & 4 & 27 & & 493 & 7 & 110 & 3 & \multicolumn{2}{|c|}{8} & 19 & 162 \\
\hline MD 139 & 17 & 19 & & 6 & 18 & 31 & 73 & 4 & 10 & & 590 & 7 & 43 & 3 & \multicolumn{2}{|c|}{9} & 2 & 108 \\
\hline MD 12 & 16 & 20 & & 6 & 18 & 39 & 94 & 2 & 26 & & 607 & 7 & 49 & 3 & \multicolumn{2}{|c|}{11} & 1 & 240 \\
\hline MD 21 & 18 & 23 & & 7 & 19 & 31 & 102 & 3 & 39 & & 594 & 9 & 72 & 4 & \multicolumn{2}{|c|}{8} & 2 & 276 \\
\hline MD 24 & 16 & 15 & & 5 & 14 & 46 & 65 & 5 & 11 & & 456 & 6 & 83 & 3 & \multicolumn{2}{|c|}{16} & 20 & 145 \\
\hline MD 66 & 18 & 16 & & 6 & 21 & 47 & 80 & 5 & 16 & & 519 & 7 & 56 & 3 & \multicolumn{2}{|c|}{9} & 15 & 171 \\
\hline MD 143 & 14 & 17 & & 7 & 16 & 26 & 74 & 3 & 29 & & 554 & 8 & 59 & 3 & \multicolumn{2}{|c|}{16} & 1 & 241 \\
\hline MD 173 & 13 & 13 & & 4 & 11 & 52 & 56 & 4 & 10 & & 473 & 5 & 58 & 3 & \multicolumn{2}{|c|}{5} & 72 & 159 \\
\hline MD 191 & 19 & 17 & & 5 & 12 & 55 & 64 & 4 & 10 & & 511 & 5 & 48 & 3 & \multicolumn{2}{|c|}{10} & 3 & 96 \\
\hline MD 231 & 19 & 18 & & 6 & 20 & 109 & 77 & 4 & 16 & & 497 & 8 & 72 & 4 & & & 38 & 170 \\
\hline MD 257 & 30 & 29 & & 7 & 20 & 132 & 69 & 4 & 16 & & 523 & 11 & 203 & 6 & & & 110 & 175 \\
\hline MD 259 & 11 & 12 & & 10 & 9 & 16 & 32 & 3 & 17 & & 467 & 5 & 81 & 2 & & & 1 & 243 \\
\hline MD 272 & 19 & 21 & & 7 & 19 & 27 & 74 & 4 & 8 & & 518 & 5 & 62 & 3 & & & 1 & 271 \\
\hline MD 276 & 19 & 18 & & 8 & 17 & 98 & 64 & 5 & 19 & & 476 & 7 & 82 & 4 & & & 88 & 97 \\
\hline MD 67 & 39 & 35 & & 9 & 25 & 46 & 54 & 3 & 9 & & 173 & 9 & 69 & 5 & & & 4 & 126 \\
\hline MD 172 & 26 & 24 & & 10 & 20 & 99 & 56 & 7 & 15 & & 389 & 7 & 77 & 4 & & & 23 & 296 \\
\hline MD 193 & 31 & 26 & & 6 & 19 & 28 & 40 & 2 & 16 & & 323 & 10 & 221 & 6 & & & 2 & 100 \\
\hline MD 222 & 22 & 21 & & 6 & 15 & 79 & 37 & 3 & 14 & & 349 & 8 & 144 & 4 & & & 41 & 161 \\
\hline MD 256 & 28 & 25 & & 6 & 20 & 41 & 53 & 3 & 23 & & 309 & 8 & 163 & 5 & & & 10 & 217 \\
\hline MD 261 & 28 & 27 & & 11 & 17 & 503 & 166 & 10 & 19 & & 420 & 10 & 169 & 5 & & & 1225 & 347 \\
\hline Sample & $\mathrm{La}$ & $\mathrm{Ce}$ & $\operatorname{Pr}$ & $\mathrm{Nd}$ & $\mathrm{Sm}$ & $\mathrm{Eu}$ & Gd & $\mathrm{Tb}$ & Dy & Ho & Er & $\mathrm{Tm}$ & $\mathrm{Yb}$ & $\mathrm{Lu}$ & Hf & $\mathrm{Pb}$ & Th & $\mathrm{U}$ \\
\hline MD 243 & 9 & 16 & 2 & 8 & 2 & 0 & 1 & 0 & 1 & 0 & 1 & 0 & 1 & 0 & 3 & 276 & 9 & 16 \\
\hline MD 139 & 10 & 17 & 2 & 8 & 2 & 0 & 1 & 0 & 1 & 0 & 1 & 0 & 1 & 0 & 1 & 37 & 10 & 17 \\
\hline MD 12 & 11 & 21 & 2 & 8 & 2 & 0 & 1 & 0 & 1 & 0 & 1 & 0 & 1 & 0 & 1 & 76 & 11 & 21 \\
\hline MD 21 & 15 & 25 & 3 & 11 & 2 & 0 & 2 & 0 & 1 & 0 & 1 & 0 & 1 & 0 & 2 & 56 & 15 & 25 \\
\hline MD 24 & 7 & 13 & 2 & 7 & 1 & 0 & 1 & 0 & 1 & 0 & 1 & 0 & 1 & 0 & 2 & 1448 & 7 & 13 \\
\hline MD 66 & 7 & 15 & 2 & 7 & 2 & 0 & 2 & 0 & 1 & 0 & 1 & 0 & 1 & 0 & 2 & 505 & 7 & 15 \\
\hline MD 143 & 10 & 20 & 2 & 8 & 1 & 0 & 1 & 0 & 1 & 0 & 1 & 0 & 1 & 0 & 1 & 62 & 10 & 20 \\
\hline MD 173 & 6 & 12 & 1 & 6 & 1 & 0 & 1 & 0 & 1 & 0 & 1 & 0 & 1 & 0 & 2 & 94 & 6 & 12 \\
\hline MD 191 & 6 & 13 & 2 & 5 & 1 & 0 & 1 & 0 & 1 & 0 & 0 & 0 & 1 & 0 & 1 & 137 & 6 & 13 \\
\hline MD 231 & 8 & 16 & 2 & 7 & 2 & 0 & 1 & 0 & 1 & 0 & 1 & 0 & 1 & 0 & 2 & 259 & 8 & 16 \\
\hline MD 257 & 13 & 24 & 3 & 12 & 2 & 1 & 2 & 0 & 2 & 0 & 1 & 0 & 1 & 0 & 5 & 881 & 13 & 24 \\
\hline MD 259 & 7 & 12 & 2 & 6 & 1 & 0 & 1 & 0 & 1 & 0 & 1 & 0 & 0 & 0 & 2 & 13 & 7 & 12 \\
\hline MD 272 & 7 & 17 & 2 & 6 & 1 & 0 & 1 & 0 & 1 & 0 & 1 & 0 & 1 & 0 & 2 & 75 & 7 & 17 \\
\hline MD 276 & 8 & 16 & 2 & 7 & 2 & 0 & 1 & 0 & 1 & 0 & 1 & 0 & 1 & 0 & 2 & 627 & 8 & 16 \\
\hline MD 67 & 9 & 18 & 2 & 8 & 2 & 1 & 2 & 0 & 2 & 0 & 1 & 0 & 1 & 0 & 2 & 199 & 9 & 18 \\
\hline MD 172 & 8 & 16 & 2 & 8 & 2 & 0 & 2 & 0 & 1 & 0 & 1 & 0 & 1 & 0 & 2 & 603 & 8 & 16 \\
\hline MD 193 & 12 & 24 & 3 & 11 & 2 & 1 & 2 & 0 & 2 & 0 & 1 & 0 & 1 & 0 & 6 & 50 & 12 & 24 \\
\hline MD 222 & 9 & 17 & 2 & 8 & 2 & 0 & 2 & 0 & 2 & 0 & 1 & 0 & 1 & 0 & 4 & 331 & 9 & 17 \\
\hline MD 256 & 12 & 22 & 3 & 9 & 2 & 0 & 2 & 0 & 2 & 0 & 1 & 0 & 1 & 0 & 4 & 234 & 12 & 22 \\
\hline MD 261 & 11 & 21 & 3 & 10 & 2 & 0 & 2 & 0 & 2 & 0 & 1 & 0 & 1 & 0 & 4 & 1691 & 11 & 21 \\
\hline
\end{tabular}



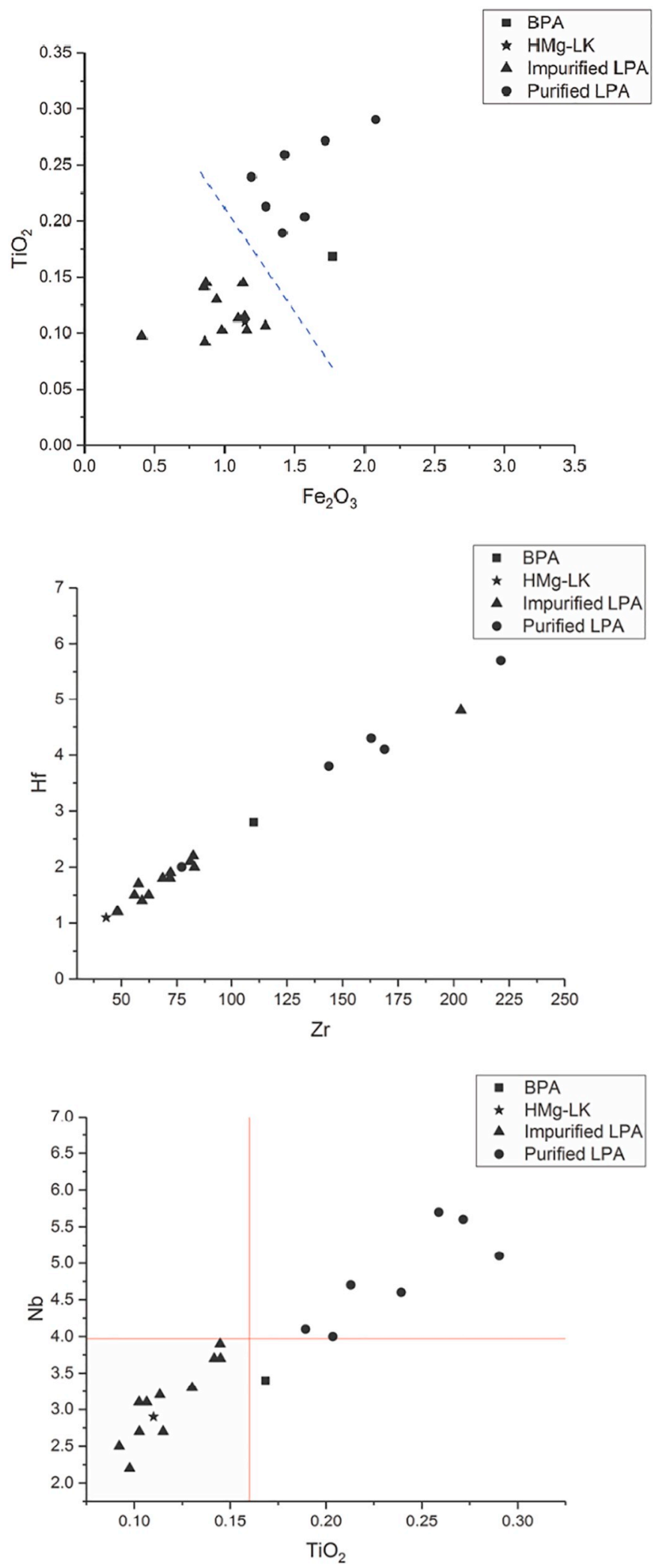

Fig. 6. Bi-plots according to LA-ICP-MS data: $\mathrm{Fe}_{2} \mathrm{O}_{3}-\mathrm{TiO}_{2}$ (top); $\mathrm{Zr}-\mathrm{Hf}$ (middle); $\mathrm{TiO}_{2}-\mathrm{Nb}$ (bottom). Oxides are represented in $\mathrm{wt} \%$, while elements in ppm.

The latter two could imply the recycling of tesserae.

There is a possibility that glass cullet, which is not rich in metalbearing colourants, was added to the glass melt. The result could be a difference in chemical composition of the glass, which do not show elevated values for lead, copper, zinc, tin and antimony. The cause of possible low values of the aforementioned elements could also be in the small amount of recycling cycles.

\subsubsection{Chemical fingerprint of the sands}

Trace elements can be considered compositionally indicative. In general, $\mathrm{Zr} \geq 70 \mathrm{ppm}, \mathrm{TiO}_{2} \geq 0.18 \mathrm{wt} \%, \mathrm{Cr} \geq 21 \mathrm{ppm}, \mathrm{V} \geq 21 \mathrm{ppm}$ and $\mathrm{Nb} \geq 4 \mathrm{ppm}$ are correlated with purified LPA glasses. Impurified LPA glasses have $\mathrm{Zr} \leq 70 \mathrm{ppm}, \mathrm{TiO}_{2} \leq 0.18 \mathrm{wt} \%, \mathrm{Cr}<20 \mathrm{ppm}$, $\mathrm{V} \leq 20 \mathrm{ppm}$ and $\mathrm{Nb} \leq 4 \mathrm{ppm}$. The exceptions from this pattern are the recycled glasses. Miranduolo samples have a strong positive correlation of $\mathrm{Fe}_{2} \mathrm{O}_{3}-\mathrm{TiO}_{2}, \mathrm{TiO}_{2}-\mathrm{Zr}, \mathrm{Zr}-\mathrm{Hf}$ and $\mathrm{TiO}_{2}-\mathrm{Nb}$ (Fig. 6). All the aforementioned correlations are explained as mineral impurities in the sandy raw material. Columbite $\left(\mathrm{FeNb}_{2} \mathrm{O}_{6}\right)$, a niobium-containing mineral, can be found selectively deposited with $\mathrm{Fe}$ - Ti bearing oxide minerals, including zircon and ilmenite. They are found in sedimentary fluvial deposits as heavy mineral placers. Columbite-bearing mineral deposits are common in geological regions characterised by granitic rocks and outcrops (Schiavon et al., 2012). On the other hand, no significant granite outcrops are present near the Miranduolo area nor near San Vettore and Germagnana glass-making factories (Constantini et al., 2005). Rare Earth Elements (REE): La, Ce, Pr, Nd, Sm, Eu, Gd, Tb, Dy, $\mathrm{Ho}, \mathrm{Er}, \mathrm{Tm}, \mathrm{Yb}$ and $\mathrm{Lu}$ give the raw material fingerprint.

They are known to be resistant to precipitation in numerous chemical reactions (Wedepohl et al., 2011a). More importantly, plant ash Na-Ca-Si glasses derive their REE from the silica sand (Wedepohl et al., 2011a). The REE's were normalised to continental crust data (Inline Supplementary Table S1) (Wedepohl, 1995).

Four different methods were used to group REE data (Inline Supplementary Table S1):

1) an average for all Miranduolo glasses (Fig. 7 - top);

2) an average for impurified and purified LPA glasses (Fig. 7 - bottom);

3) according to aluminium concentration: each group is assigned for every $0.5 \mathrm{wt} \%$ of $\mathrm{Al}_{2} \mathrm{O}_{3}$;

4) as the third method but without recycled glasses (Fig. 8).

Comparing the third and fourth method, the distinction can be only sought in the group 3 as it contained two recycled samples.

The REE were compared with the available published data from Wedepohl et al. (Fig. 7, Fig. 8) (Wedepohl et al., 2011a; Wedepohl et al., 2011b). Miranduolo's REE seem to be comparable with wood ash glasses (K-Ca-Si) not Na-Ca-Si glasses (Fig. 7). Negative Eu anomaly occurs as $\mathrm{Eu}^{2+}$ and separates from the other REEs (Wedepohl et al., 2011a). Those anomalies are often in granites where $\mathrm{Eu}^{2+}$ is incorporate in Ca-plagioclases (Wedepohl et al., 2011a). Every Miranduolo REE group displays this anomaly except group 5 and 13th century Venetian glass from Höxter (Fig. 8) (Wedepohl et al., 2011b). Negative Ce anomaly is "...formed under oxidizing conditions in rocks that late in their history reacted with seawater..." (Wedepohl et al., 2011a). This anomaly is not noted in groups 5 and 6 (Fig. 8) (Wedepohl et al., 2011b).

3.4.3. Rubidium and arsenic as dating discriminants for Tuscan glassmaking?

Cagno et al. (Cagno et al., 2010) use $\mathrm{K}_{2} \mathrm{O}-\mathrm{Rb}$ plot for LPA glasses as a dating discriminant:

1) $\mathrm{Rb} \leq 30 \mathrm{ppm}$ dated to 13 th -14 th century $\mathrm{CE}$

2) $\mathrm{Rb}>30 \mathrm{ppm}$ dated to 15 th -16 th century $\mathrm{CE}$.

Additionally, the authors discuss the occurrence of LPA glasses in the 13th/14th and the occurrence of BPA glasses in the 15th century (Cagno et al., 2010). The main distinction between them in arsenic concentrations: 

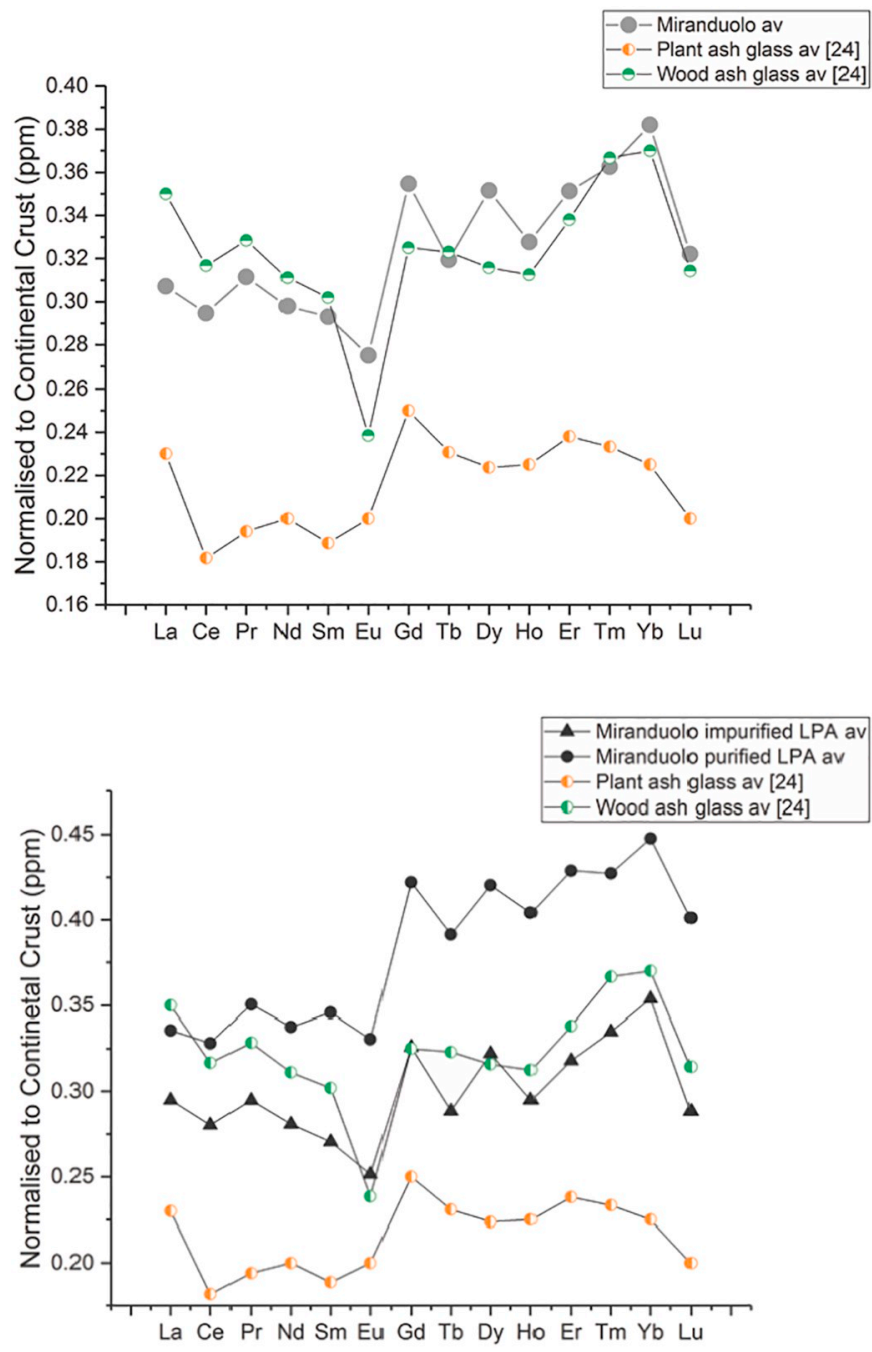

Fig. 7. Plot of Mirandoulo's REE average (top), impurified and purified LPA glasses (bottom) compared to wood and plant ash glass average from (Wedepohl et al., 2011a).

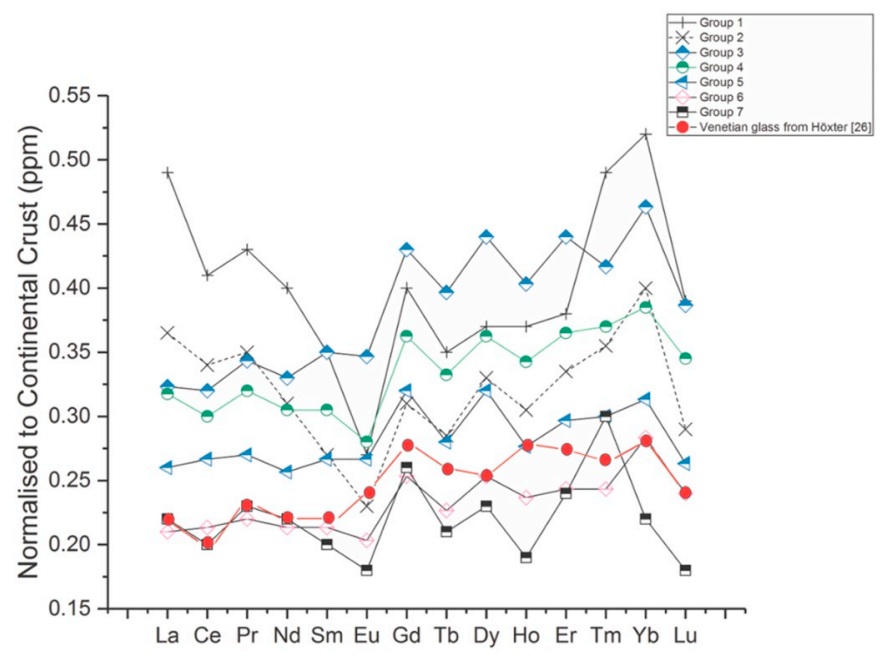

Fig. 8. Normalised REE abundances of Miranduolo glass groups according to alumina concentration without recycled samples. The data is compared to average abundances of 13th century Venetian glass found in Höxter, Germany (Wedepohl et al., 2011b).

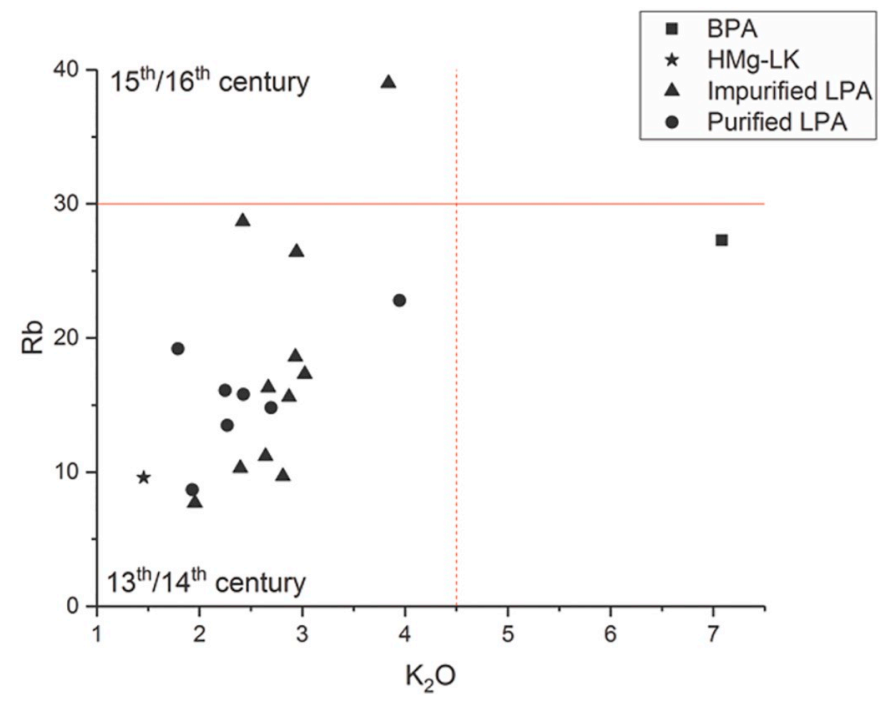

Fig. 9. $\mathrm{K}_{2} \mathrm{O}-\mathrm{Rb}$ plot of Miranduolo glasses according to LA-ICP-MS data. The data is presented as oxide in $\mathrm{wt} \%$ and element in $\mathrm{ppm}$.

\section{$\diamond$ As $<10$ ppm in LPA glasses}

$\diamond$ As $>30 \mathrm{ppm}$ in BPA glasses.

All Miranduolo LPA glasses have $\mathrm{Rb}<30 \mathrm{ppm}$. The only exception is MD 21 (Fig. 9). A coeval glass t_62 from San Vettore is also an exception with rubidium of $47 \mathrm{ppm}$ (Cagno et al., 2010). Apart from these two discrepancies, the glasses from 13th-14th century Tuscan sites including Miranduolo have rubidium concentrations below $30 \mathrm{ppm}$. Hence, there is a possibility that glasses MD 21 and t_62 were incorrectly dated or rubidium plot cannot be used as a dating discriminant for LPA glasses.

Only one BPA glass has been recovered at Miranduolo: MD 243. It has arsenic levels of $4 \mathrm{ppm}$ and rubidium levels of $27 \mathrm{ppm}$ (Inline Supplementary Table S1). Therefore, this BPA glass shows concentrations that are characteristic of 13th-14th century LPA glasses. According to the current data no firm conclusions can be made.

\subsubsection{Colourants}

The $\mathrm{Fe}_{2} \mathrm{O}_{3}-\mathrm{TiO}_{2}$ strong positive correlation indicates that the glasses obtained their colour due to iron impurities present in the sands. On the other hand, intentional input of manganese was added to decolourise

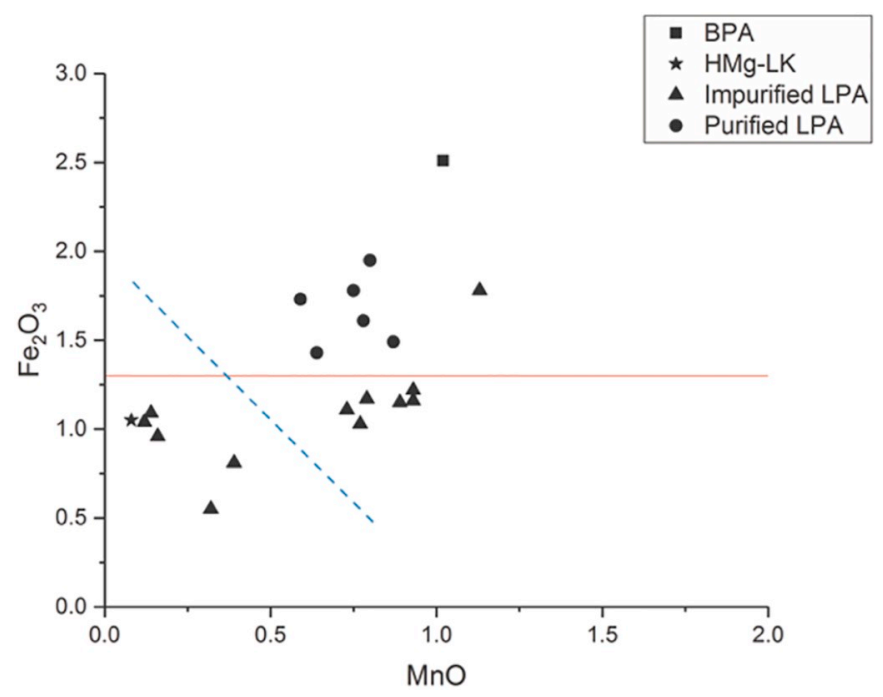

Fig. 10. Plot of $\mathrm{Fe}_{2} \mathrm{O}_{3}$-MnO. PIXE-PIGE data are presented in wt\%. 


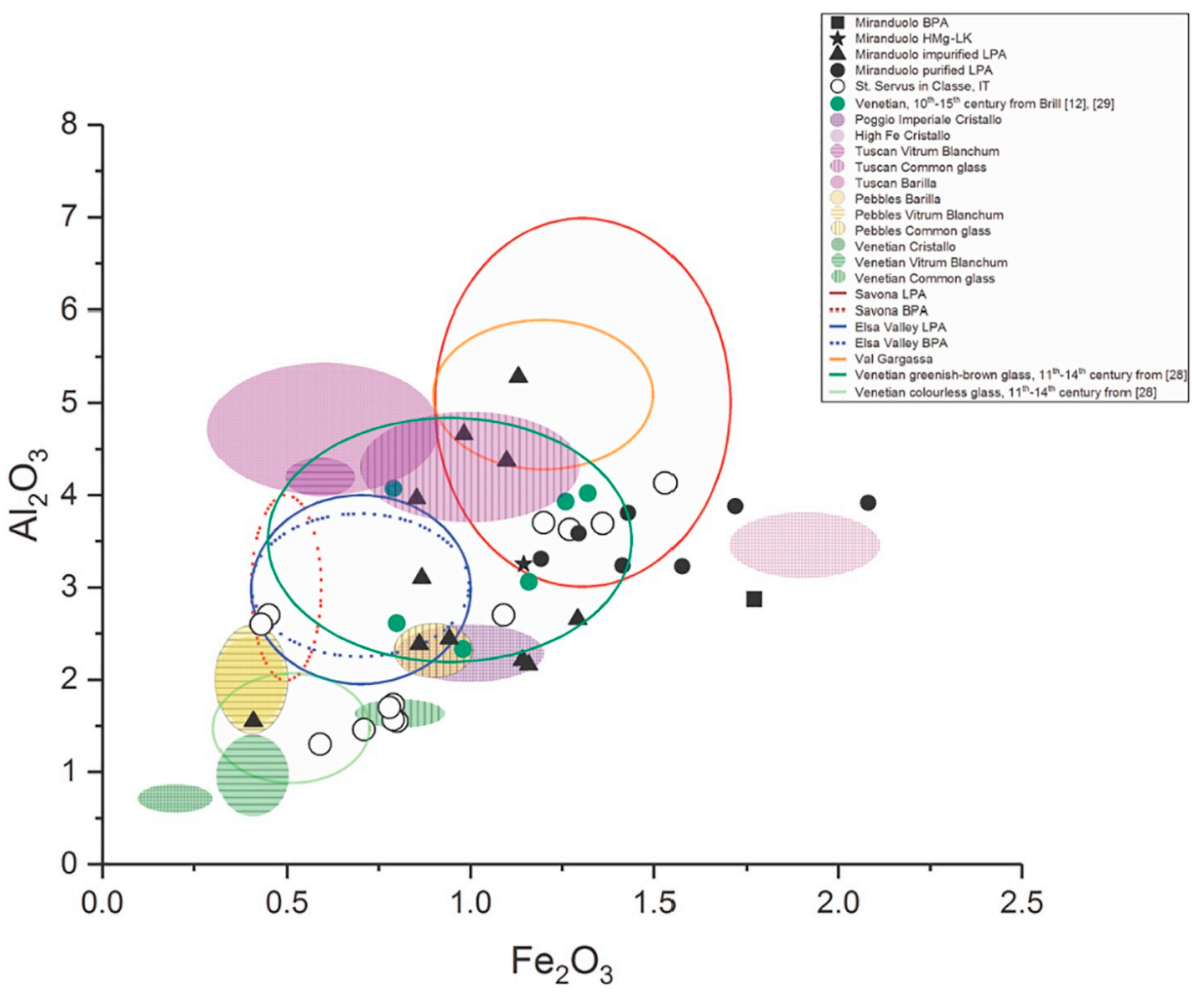

Fig. 11. Comparison of concentration between coeval Italian glasses and Venetian glass with a broader time-frame. All the areas are a representation of an average composition with the standard deviation; all the points are exact values (wt $\%)$. For details of the sites: (Cagno et al., 2010; Cagno et al., 2008; Verità, 2013; Cagno et al., 2012b; Brill, 1999a; Vandini et al., 2018; Brill, 1999b). the glasses (Fig. 10). Manganese as a decolouriser is acknowledged to be used in Tuscan glass recipes by the end of 13th century (Gimeno et al., 2008; Gimeno et al., 2010).

\subsection{Coeval Italian sites}

The results were compared with coeval Italian sites (Cagno et al., 2010; Cagno et al., 2008; Verità, 2013; Cagno et al., 2012b; Brill, 1999a; Vandini et al., 2018; Brill, 1999b).

All the sites have similar composition of major elements showing that there was a glass recipe which was used throughout the Apennines (Fig. 11). One has to take in consideration that in Medieval times the glassmakers did not have commercially standardised raw materials (Smedley and Jackson, 2002). Between 11th and 14th century Venetian glassmakers used more impure raw silica sources comparing to the famous glasses made with Ticino pebbles. These "impure" Venetian glasses had iron and alumina concentrations of $\mathrm{Fe}_{2} \mathrm{O}_{3}>0.80 \mathrm{wt} \%$ and $\mathrm{Al}_{2} \mathrm{O}_{3}>2.5 \mathrm{wt} \%$ as Miranduolo glasses (Verità, 2013; Brill, 1999a; Brill, 1999b). Only MD 259 has a "purer" sand with $\mathrm{Fe}_{2} \mathrm{O}_{3}<0.5 \mathrm{wt} \%$. and $\mathrm{Al}_{2} \mathrm{O}_{3}<2.5 \mathrm{wt} \%$. The titanium, zirconium, cerium and hafnium concentrations do not correspond to the Venetian glasses made with Ticino pebbles (Cagno et al., 2010; Smedley and Jackson, 2002; Šmit et al., 2005).

The major and minor elements of MD 259 correspond composition of 90.48 and 90.49 glasses at Santa Cristina glass-making workshop (Brianese et al., 2005). Additionally, 90.4 8, 90.49 and MD 259 are colourless and display visible iridescence effect on the surface. On the other hand, the non-recycled FA1 and FA2 glasses from Nogara also have the same major and minor chemical composition. Other 13th 14th century Nogara glasses tend to be recycled with copper, tin, antimony and lead above 100 ppm (Silvestri and Marcante, 2011).

Savona glasses have consistent different concentrations of copper, arsenic, rubidium, zirconium, niobium and barium than Miranduolo glasses (Cagno et al., 2012a).

The coeval Germagnana glasses (t_92 and t_95) contain $\mathrm{MgO}>6.5 \mathrm{wt} \%$ (Cagno et al., 2010).

Although the major and minor elemental composition of glasses t_90 and t_91 from San Vettore is equal to Miranduolo, the barium and strontium levels are different (Cagno et al., 2010). San Vettore barium $(>1000 \mathrm{ppm})$ and strontium (>750 ppm) concentrations are considerably higher than in Miranduolo's glasses (Cagno et al., 2010).

Rocca di Campiglia glasses (t_58-59 and t_63) and prunted beakers (N5-7) from St. Severus in Classe near Ravenna (Emilia-Romagna region) have major, minor and trace elements that seem to be perfectly overlapping with Mirnaduolo's (Cagno et al., 2010; Vandini et al., 2018; Brill, 1999b). It is probable that all three sites have been supplied by the same glass-making factory.

The REE of 13th century Venetian glass found in Höxter, Germany displays a significantly different fingerprint than Miranduolo glasses. Only group 5 does not have the Eu anomaly as the Venetian Höxter glasses (De Francesco et al., 2014).

Unfortunately, the REE fingerprint for the quarried sands and coeval Italian glasses is not available. Hence, the exact comparison of quartz sand signatures is not possible. Therefore, we leave it probable that Tuscan glass-making factories were suppliers for Miranduolo castle.

\subsection{Categorical data}

The glasses have been distinctively selected according to the following categorical data parameters: typology, colour, thickness, settlement's phase of recovery, settlements area of recovery with socioeconomic and political distinction - noble family area and village area. No connection was found between the categorical and the chemical data.

\section{Conclusions}

Three techniques were used in this study to evaluate glass homogeneity, presence and intensity of de-alkalisation, and chemical composition to understand glass production methodologies (decolourants, colourants, extent of recycling, raw materials), provenance and can glass be associated with socio-economic markers present at Miranduolo. VP-SEM-EDS, although a semi-quantifying in nature with overestimation of sodium, aluminium, magnesium and underestimation of 
silica, yielded potassium and calcium values that correspond to LA-ICPMS data. On the other hand, PIXE/PIGE calcium values seem to be underestimated comparing to the two. Due to this discrepancy all subgrouping was based on LA-ICP-MS data because it displayed highest accuracy and precision.

The glass finds from Miranduolo are typical 13th-14th century vessel forms that are found at coeval Italian sites. The skill of the glassmaker is accentuated with shapes blown down to $350 \mu \mathrm{m}$. In order to blow the glass as thin the glassmaker should have decades of handson experience. The major and minor elements data displays similarities in the glass production. Plant ashes and "impure" sands were used throughout Tuscany, Liguria and Venice. This could imply the existence of a "recipe trend" and/or the movement of Venetian glass masters to Tuscany. It is exactly from the 13th century that Tuscan glass-making workshops were established and started to flourish.

The glasses mainly do not display properties of recycling indicating that the glasses went through the whole glass-making process from obtaining raw materials to forming them into final product. But there is a possibility that a glass cullet (possibly Venetian), poor in metalbearing colourants, was added to the glass melt affecting only major chemical composition. The recycling markers would not be elevated if there was a small amount of recycling cycles. Due to the raw materials used, the natural tint was trying to be diminished and/or reduced with manganese is well known in Tuscan glass recipes by the end of 13th century.

There is a notable difference in chemical composition between two sub-types of LPA glasses. Trace elements consistently show the difference in the sand sources used for impurified and purified glasses, with the impurified LPA glasses being made with a purer sand source than the purified LPA glasses. The correlations of $\mathrm{K}_{2} \mathrm{O}-\mathrm{CaO}$ and $\mathrm{K}_{2} \mathrm{O}-\mathrm{MgO}$, $\mathrm{CaO}-\mathrm{Ba}, \mathrm{MgO}-\mathrm{Ba}, \mathrm{K}_{2} \mathrm{O}-\mathrm{Ba}$ and $\mathrm{CaO}-\mathrm{MgO}$ in impurified LPA glasses are different that those found in both Salsola and non-Salsola plant ashes. This leaves the probability that the high calcium content in the glass is not related to input of the plant ashes but to the silica sources, or to an intentional adding of a calcium source in form of shells or limestone. The possibility is that calcium rich sands of La Casina La Cava quarry near Gambassi, which could have been subjected to purification by washing, were used. On the other hand, the purified LPA glasses were made with more impure sand sources. Lower concentrations of calcium and a constant concentration of magnesium indicate that a purification process of the ashes might have taken place.

The REE fingerprint shows that different sands were used implying that the glasses could have come from multiple factories. One should take into consideration the possibility of the existence of glass-making factories that have still not been excavated and those that are permanently destroyed. Additionally, the timespan of one century seems very long in terms of data comparisons as different batches would have been manufactured on a daily basis. This implies that the sand could have been obtained from different places and/or imported outside the glassmaking workshops vicinity. The use of Ticino pebbles as a raw silica source can be excluded as a possibility. As we do not know the exact concertation of REE of the glasses from other coeval Italian sites, only speculation is possible. What seems the most probable option is that multiple Tuscan glass-making centres were the suppliers for Miranduolo.

\section{Acknowledgements}

Ivona Posedi gratefully acknowledges the financial support from EACEA agency of EC under FPA 2013-0238 through ARCHMAT EMMC scholarship. Financial support by the Access to Research Infrastructures activity in the H2020 Programme of the EU (IPERION CH Grant Agreement) is gratefully acknowledged. We are especially indebt to Marco Valenti, Alessandra Nardini and Manuelle Putti from the Department of Historical Sciences and Cultural Heritage for providing glass samples and to the research staff at the MTA Atomki: Zita Szikszai,
Anikó Angyal, László Csedreki, Enikő Furu, Róbert Huszánk, Enikő Papp and Zoltán Szoboszlai. Special thanks to Guilhem Mauran for assistance with the methodology and Melina Smirniou for critically evaluating the manuscript prior to submission. Constructive comments from two reviewers are gratefully acknowledged; any remaining errors are our own responsibility.

\section{Appendix A. Supplementary data}

Supplementary data to this article can be found online at https:// doi.org/10.1016/j.jasrep.2019.101878.

\section{References}

Barkoudah, Y., Henderson, J., 2008. Plant ashes from Syria and the manufacture of ancient glass: ethnographic and scientific aspects. Journal of glass studies 48, 297-321.

Basso, E., et al., 2009. Composition of the base glass used to realize the stained glass windows by Duccio di Buoninsegna (Siena Cathedral, 1288-1289 AD): a geochemical approach. Mater. Charact. 60 (12), 1545-1554.

Bianchin, S., et al., 2005a. Medieval and renaissance glass technology in Valdelsa (Florence). Part 2: vitreous finds and sands. J. Cult. Herit. 6 (1), 39-54.

Bianchin, S., et al., 2005b. Medieval and renaissance glass technology in Valdelsa (Florence). Part 3: vitreous finds and crucibles. J. Cult. Herit. 6 (2), 165-182.

Brianese, N., Casellato, U., Fenzi, F., Sitran, S., Vigato, P.A., Mendera, M., 2005. Medieval and Renaissance glass technology in Tuscany. Part 4: the XIVth sites of Santa Cristina (Gambassi-Firenze) and Poggio Imperiale (Siena). J. Cult. Herit. 6 (3), 213-225.

Brill, R.H., 1999a. Chemical Analyses of Early Glasses. vol. 2 Corning Museum of Glass, Corning, N.Y.

Brill, R.H., 1999b. Chemical Analyses of Early Glasses Vol 1. vol. 1 Corning Museum of Glass, Corning, N.Y.

Brill, R.H., Pongracz, P., 2004. Stained glass from Saint-Jean-des-Vignes (Soissons) and comparisons with glass from other medieval sites. Journal of glass studies 46, 115-144.

Cagno, S., Janssens, K., Mendera, M., 2008. Compositional analysis of Tuscan glass samples: in search of raw material fingerprints. Anal. Bioanal. Chem. 391 (4), 1389-1395.

Cagno, S., Mendera, M., Jeffries, T., Janssens, K., 2010. Raw materials for medieval to post-medieval Tuscan glass-making: new insight from LA-ICP-MS analyses. J. Archaeol. Sci. 37, 3030-3036.

Cagno, S., Brondi Badano, M., Mathis, F., Strivay, D., Janssens, K., 2012a. Study of medieval glass fragments from Savona (Italy) and their relation with the glass produced in Altare. J. Archaeol. Sci. 39, 2191-2197.

Cagno, S., Favaretto, L., Mendera, M., Izmer, A., Vanhaecke, F., Janssens, K., 2012b. Evidence of early medieval soda ash glass in the archaeological site of San Genesio (Tuscany). J. Archaeol. Sci. 39 (5), 1540-1552.

Campbell, J.L., Boyd, N.I., Grassi, N., Bonnick, P., Maxwell, J.A., 2010. The Guelph PIXE software package IV. Nuclear instruments \& methods in physics research B 268 (20), 3356-3363.

Casellato, U., et al., 2003. Medieval and renaissance glass technology in Valdelsa (Florence). Part 1: raw materials, sands and non-vitreous finds. J. Cult. Herit. 4 (4), 337-353.

Castello di Miranduolo Castello di Miranduolo. [Online]. Available: http:// archeologiamedievale.unisi.it/miranduolo/mediacenter, Accessed date: 31 August 2016.

Reperti vitrei Castello di Miranduolo. Castello di Miranduolo [Online]. Available. http:// archeologiamedievale.unisi.it/miranduolo/lo-scavo/documentazione/i-materiali/ vetri?field_num_inv_vetri_value $=$ \&field_area_rif_ceramica_nid $=$ All\&field_us reference_nid = All\&field_periodo_ceramica_nid = All\&field_struttura_rif_ceramica nid=All\&field_forma, Accessed date: 31 August 2016 .

A. Constantini et al., Note Illustrative della Carta Geologica d'Italia alla scala 1:50.000. Foglio 296- Siena. Roma: Università degli Studi di Siena e ISPRA-Servizio Geologico d' Italia, 2005.

De Francesco, A.M., Scarpelli, R., Del Vecchio, F., Giampaola, D., 2014. Analysis of early medieval glass from excavations at 'Piazza Bovio', Naples (Italy). Archaeometry 56 (SUPPLS1), 137-147.

Duckworth, C.N., de la Llave, R. Córdoba, Faber, E.W., Edwards, D.J. Govantes, Henderson, J., 2015. Electron microprobe analysis of 9th-12th century Islamic glass from Córdoba, Spain. Archaeometry 57 (1), 27-50.

A. Franjić. Personal communication, Sept. 2018.

Fronza, V., Valenti, M., 2015. Chiusdino (SI). Castello di Miranduolo: relazione preliminare 2015. In: Notiziario della Soprintendenza per i Beni Archeologici della Toscana, Notizie. vol. 11. pp. 401-403.

Gimeno, D., et al., 2008. From Siena to Barcelona: deciphering colour recipes of Na-rich Mediterranean stained glass windows at the XIII-XIV century transition. J. Cult. Herit. 9, e10-e15.

Gimeno, D., et al., 2010. Caracterización química de la vidriera del rosetón del Duomo de Siena (Italia, 1288-1289). Boletin de la Sociedad Espanola de Ceramica y Vidrio 49 (3), 205-213.

Henderson, J., 1988. Electron probe microanalysis of mixed-alkali glasses. Archaeometry 30 (1), 77-91.

Janssens, K.H.A., 2013. Modern Methods for Analysing Archaeological and Historical 
Glass. John Wiley \& Sons.

Pollard, A.M., Heron, C., 2008. Archaeological Chemistry. Royal Society of Chemistry, Cambridge.

Schiavon, N., et al., 2012. A combined multi-analytical approach for the study of Roman glass from South-West Iberia: synchrotron micro-XRF, external-PIXE/PIGE and BSEM-EDS. Archaeometry 54 (6), 974-996.

Schibille, N., Freestone, I.C., 2013. Composition, production and procurement of glass at San Vincenzo al Volturno: an early Medieval monastic complex in Southern Italy. PLoS One 8 (10), 1-13.

Silvestri, A., Marcante, A., 2011. The glass of Nogara (Verona): a 'window' on production technology of mid-Medieval times in Northern Italy. J. Archaeol. Sci. 38, 2509-2522.

Simon, A., et al., 2011. PIXE analysis of Middle European 18th and 19th century glass seals. X-Ray Spectrom. 40 (3), 224-228.

Smedley, J.W., Jackson, C.M., Feb. 2002. Medieval and post-medieval glass technology: batch measuring practices. Glass Technol. 43 (1), 22-27.

Šmit, Ž., Janssens, K., Bulska, E., Wagner, B., Kos, M., Lazar, I., 2005. Trace element fingerprinting of façon-de-Venise glass. Nucl. Instrum. Methods Phys. Res. B 239 (1), 94-99.

"Trace Elements (wafer form)," National Institute for Standards and Technology.

[Online]. Available: https://www-s.nist.gov/srmors/viewTableH.cfm?tableid $=90$.
Valenti, M. (Ed.), 2008. Miranduolo in alta Val di Merse (Chiusdino -SI). Archeologia su un sito di potere del Medioevo toscano. All'Insegna del Giglio s. a. s, Firenze.

Valenti, M. (Ed.), 2010. Miranduolo in alta Val di Merse (Chiusdino - SI). Archeologia su un sito di potere del Medioevo toscano, Ebook. University of Siena.

Vandini, M., Chinni, T., Fiorentino, S., Galusková, D., Kaňková, H., 2018. Glass production in the Middle Ages from Italy to Central Europe: the contribution of archaeometry to the history of technology. Chem. Pap.

Verità, M., 2013. Venetian Soda Glass. In: Janssens, K. (Ed.), Modern Methods for Analysing Archaeological and Historical Glass. vol. 1. pp. 515-536.

Wagner, B., Nowak, A., Bulska, E., Hametner, K., Günther, D., 2012. Critical assessment of the elemental composition of Corning archeological reference glasses by LA-ICP-MS Anal. Bioanal. Chem. 402 (4).

Wedepohl, K.H., 1995. The composition of the continental crust. Geochim. Cosmochim. Acta 59 (7), 1217-1232.

Wedepohl, K.H., Simon, K., Kronz, A., 2011a. The chemical composition including the Rare Earth Elements of the three major glass types of Europe and the Orient used in late antiquity and the Middle Ages. Chemie der Erde - Geochemistry 71 (3), 289-296.

Wedepohl, K.H., Simon, K., Kronz, A., 2011b. Data on 61 chemical elements for the characterization of three major glass compositions in late antiquity and the middle ages. Archaeometry 53 (1), 81-102. 